\title{
Disease Note
}

\section{Diseases Caused by Fungi and Fungus-Like Organisms}

First Report of Colletotrichum karstii Causing Anthracnose on Strawberry in Brazil

\author{
V. F. Soares, A. C. Velho, A. Carachenski, P. Astolfi, and M. J. \\ Stadnik
}

Laboratório de Fitopatologia, Centro de Ciências Agrárias, Universidade Federal de Santa Catarina, CP 476, 88034-001, Florianópolis-SC, Brazil

Funding: Funding was provided by Coordenação de Aperfeiçoamento de Pessoal de Nível Superior. Plant Dis. 105:3295, 2021; published online as https://doi.org/10.1094/PDIS-03-21-0518-PDN. Accepted for publication 19 April 2021.

Strawberry (Fragaria $\times$ ananassa Duch.) is one of the most important fruit crops worldwide. With increasing cultivated area in the last decades, Brazil has become the largest strawberry producer in South America. Anthracnose caused by Colletotrichum spp. has been considered one of the most destructive diseases in Brazil. In May 2019, irregular and circular dark brown leaf spots sometimes associated with chlorosis and petiole necrosis were observed on strawberry plants (cv. Pircinque) organically cultivated in Santa Catarina state, Brazil $\left(27^{\circ} 45^{\prime} 40^{\prime \prime} \mathrm{S}\right.$, $\left.49^{\circ} 59^{\prime} 06^{\prime \prime} \mathrm{W}\right)$. The Colletotrichum isolate was obtained from leaf tissue, and a monosporic culture was grown on potato dextrose agar at $25^{\circ} \mathrm{C}$ and a 12-h photoperiod under near ultraviolet light. Colonies at the age of 15 days showed upper surface color varying from white to orange and the reverse side grayish to orange. Conidia were hyaline, cylindrical with rounded ends, 13.9 to $9.2 \times 4.2$ to $6.7 \mu \mathrm{m}(\bar{x}=11.3 \times 5.2, n=$ $100)$. Perithecia were produced in vitro, and their diameter ranged from 265.2 to $142.5 \mu \mathrm{m}(\bar{x}=198.4)$. Asci were 47.3 to $39.9 \times 5.2$ to $7.2 \mu \mathrm{m}$ $(\bar{x}=42.8 \times 5.9, n=50)$, and ascospores 12.6 to $8.1 \times 4.3$ to $2.1 \mu \mathrm{m}(\bar{x}=$ $10.3 \times 2.9, n=100)$. To confirm pathogenicity, 90-day-old plants of strawberry (cv. Pircinque) were inoculated by spraying a suspension of $1 \times 10^{6}$ conidia/ml, incubated in a moist chamber in the dark for $48 \mathrm{~h}$, and then kept in a greenhouse for further 30 days. Plants sprayed with sterile distilled water served as a control. Additionally, detached leaves were inoculated with six drops of $10 \mu \mathrm{l}\left(1 \times 10^{6}\right.$ conidia/ml $)$ onto the abaxial surface and incubated in a moist chamber at $25^{\circ} \mathrm{C}$ and $12-\mathrm{h}$ photoperiod for 15 days. Inoculated plants exhibited the first symptoms in both leaves and petioles at 15 days after inoculation (dai). On leaves, irregular and circular dark brown spots evolved to necrotic lesions and were frequently surrounded by chlorotic halos. On petioles, lesions were reddish-brown, elongated, and depressed. Typical anthracnose symptoms on fruits at 6 dai showed as circular, slightly sunken lesions that enlarged over time and produced an abundant orange mucilaginous mass of acervuli and conidia, and after 20 days, fruits became mummified. In the detached-leaf assay, symptoms appeared at 7 dai with the presence of circular dark brown lesions measuring 1 to $15 \mathrm{~mm}$ and then evolved to necrosis. The same pathogen was consistently reisolated from the inoculated leaves, petioles, and fruits and was confirmed by morphological characterization and molecular assays as described in this note. A representative isolate (MANE189) was molecularly identified using genomic regions of actin, $\beta$-tubulin, calmodulin, glyceraldehyde-3-phosphate-dehydrogenase, glutamine synthetase, and the internal transcribed spacer. Nucleotide sequences exhibited 100\% homology to the typical Colletotrichum karstii strains (CBS:127535, CBS:128500, and ML1792) and were deposited in the GenBank database (MW396420, MW396430, MW396460, MW396440, MW396450, and MW331606). This species belongs to the $C$. boninense species complex (Damm et al. 2012) and was previously reported causing anthracnose on strawberry leaves in Taiwan (Chung et al. 2020). To our knowledge, this is the first report of $C$. karstii causing anthracnose on strawberry in Brazil. The accurate identification of the pathogen will assist in disease management and resistance breeding.

\section{References:}

Chung, P.-C., et al. 2020. Sci. Rep. 10:14664.

Damm, U., et al. 2012. Stud. Mycol. 73:1.

The author(s) declare no conflict of interest.

$e$-Xtra

Keywords: anthracnose, Fragaria $\times$ ananassa, Colletotrichum spp. strawberry

${ }^{\dagger}$ Indicates the corresponding author.

M. J. Stadnik; marciel.stadnik@ufsc.br 